\title{
Communication preferences in patients with fibromyalgia syndrome: descriptive results and patient characteristics as predictors
}

This article was published in the following Dove Press journal:

Patient Preference and Adherence

31 January 2014

Number of times this article has been viewed

\section{Antje Ullrich \\ Johannes Hauer \\ Erik Farin}

Medical Center, University of Freiburg, Institute for Quality Management and Social Medicine, Freiburg, Germany
Correspondence: Antje Ullrich Medical Center, University of Freiburg, Institute for Quality Management and Social Medicine, Engelbergerstr. 2I, D-79106 Freiburg, Germany

Tel +49 76I 27074870

Fax +4976I 27073310

Email antje.ullrich@uniklinik-freiburg.de
Background: Communication with patients with fibromyalgia syndrome (FMS) is often considered difficult. The primary objective of this explorative study was to describe the communication preferences of FMS patients in comparison with other chronic diseases, and the secondary objective was to identify patient-related predictors of those communication preferences.

Methods: A total of 256 FMS patients were asked to fill out the KOPRA [(Kommunikationspraeferenzen), communication preferences of patients with chronic illness] questionnaire at the beginning of their rehabilitation, answering questions about their communication preferences. The KOPRA's descriptive parameters were calculated and compared with other diagnosis groups. In order to include as many influencing factors as possible, data on patient-related sociodemographic, medical, pain impact and psychologic variables were gathered. A hierarchical regression analysis with four steps was performed to identify patient-related predictors of patients' communication preferences.

Results: FMS patients consider an open and patient-centered communication style to be especially important. Emotionally supportive communication and communication about personal circumstances are important for FMS patients, but the preferences of individual patients vary widely. FMS patients reveal higher values in all the subdimensions of communication preferences compared with patients with low back pain or chronic ischemic heart disease. Only a few variables appear to predict patient communication preferences. The explained variance ranged from $3.1 \%$ to $9.7 \%$. Psychologic variables have been identified as predictors in conjunction with all communication preferences.

Conclusion: Health care providers who communicate with FMS patients should employ an open and patient-centered communication style, and affective communication components should be adapted to accommodate each patient.

Keywords: patient-provider communication, fibromyalgia syndrome, patient communication preferences, predictors

\section{Introduction}

Ever greater research efforts are being invested in examining patient-provider communication. Communication between patients and their health care providers is now considered the "royal pathway to patient-centered medicine", ${ }^{1}$ becoming a key component in health care of the chronically ill.

Patients with noninflammatory conditions such as fibromyalgia syndrome (FMS) pose a particular challenge for their health care providers. FMS is a chronic disease characterized by widespread musculoskeletal pain, disturbed sleep, reduced mental functioning and depressed mood. ${ }^{2}$ Although recent progress has been made in improving the diagnostic criteria and treatment of FMS, ${ }^{2}$ providers still encounter difficulties treating patients with this condition. For many patients with FMS it is very important 
to get a somatic diagnosis from their health care providers, but FMS often has no identified (somatic) cause. ${ }^{3}$ In a study by Perrot et al, ${ }^{4}$ over half of the health care providers queried (53\%) admitted to having difficulties in diagnosing FMS. There are some possible reasons for this result, eg, the disease's still unclear etiology and pathogenesis, and an often subjective diagnosis. ${ }^{5}$ Given that there are few objectivelymeasurable criteria for FMS, health care providers must rely on patients' subjective descriptions of their symptoms and their impacts. Many physicians characterize FMS patients as "interactionally difficult". ${ }^{6}$ Choy et al reported that $59 \%$ of the patients with FMS in their study admitted to having trouble discussing their symptoms with their health care providers. ${ }^{7}$ Reasons for this may be the diffuse nature of FMS symptoms, and negative experiences with the health care system. Five years usually pass between the first experience of pain and first diagnosis. ${ }^{7,8}$ Encounters between FMS patients and health care providers are often associated with patients' feelings of disappointment, dissatisfaction and rejection. ${ }^{9}$ These perceptions may be triggered by divergent subjective illness beliefs on the part of health care providers and patients. ${ }^{3}$ Dissatisfaction with one provider leads to more frequent contacts with other health care providers (called "doctor shopping"), ${ }^{7}$ thus incurring a higher socioeconomic burden. ${ }^{10}$

A deeper understanding of the nature of the communication between the patient and provider seems very much worth pursuing. Several studies have demonstrated that therapeutic decisions made in concert with patients (shared decisionmaking, or SDM $)^{11}$ can lead to a better relationship. ${ }^{12}$ Further patients cite courtesy, respect and engagement as other important aspects of successful communication between them and their health care providers. ${ }^{13}$ Researchers have also reported an association between effective communication on the one hand and patient satisfaction, adherence and various health outcomes on the other. ${ }^{14-16}$

One factor, determining whether a provider's communication behavior is being assessed as either positive or negative, is the patient's communication preference. ${ }^{17}$ Patient-provider communication is influenced by each patient's interindividual and intra-individual needs and preferences in relationship to the provider's communication style. Each patient has slightly different expectations regarding conversations with his or her provider and the extent of participation in medical decisionmaking. The provider could adapt his or her communication behavior to the needs of FMS patients better by possessing a deeper understanding of their communication preferences. If the health care provider can fulfill the patient's expectations and respect his or her preferences, this may affect patient satisfaction positively. ${ }^{18}$ To the best of our knowledge, no study has examined the communication preferences of patients with FMS in detail so far.

The extent to which communication preferences correlate with patient-related factors has not been unequivocally defined. Some researchers have investigated the relationship between sociodemographic, clinical, psychologic or other lifestyle variables, and patient preferences for participation (ie, an active versus a passive role). ${ }^{19}$ The results show, that the probability of desiring an active role in the discussion falls significantly with increasing age and rises with increasing educational status. Sex and disease severity also influence preferences for participation. Patient-related factors only explain a minor proportion of the variance in patient preference. ${ }^{20,21}$ By identifying patient-related predictors, health care providers may better perceive initial indications of a patient's communication preferences.

All these observations led us to our two explorative questions:

1. What communication preferences do FMS patients have, and how do they differ from patients with other chronic diseases?

2. Which patient-related factors predict the communication preferences of FMS patients?

\section{Materials and methods \\ Sample and design}

Our consecutive sample consisted of 256 patients whose primary diagnosis was fibromyalgia syndrome (International Classification of Diseases version 10: M79.7) ${ }^{22}$ and who were undergoing treatment from August 2011 to July 2012 as inpatients in a German rehabilitation center (RehaKlinikum Bad Säckingen GmbH, Bad Säckingen). FMS had been diagnosed according to the 1990 American College of Rheumatology criteria. ${ }^{23}$ All patients with FMS were asked to complete a questionnaire at the beginning of rehabilitation. Our patient questionnaire was given only to patients able and willing to fill out this questionnaire (informed consent). A total of $n=406$ eligible FMS patients were asked to participate. Figure 1 shows the participant flow in this study.

Table 1 provides information (sociodemographic, medical, pain impact and psychologic variables) on the participants. Not surprisingly, significantly more women participated in the study than men. Population studies show that the femaleto-male ratio for FMS varies between $2-21: 1 .^{24}$ The study was approved by the Ethics Committee of the University of Freiburg (approval number 172/10). 


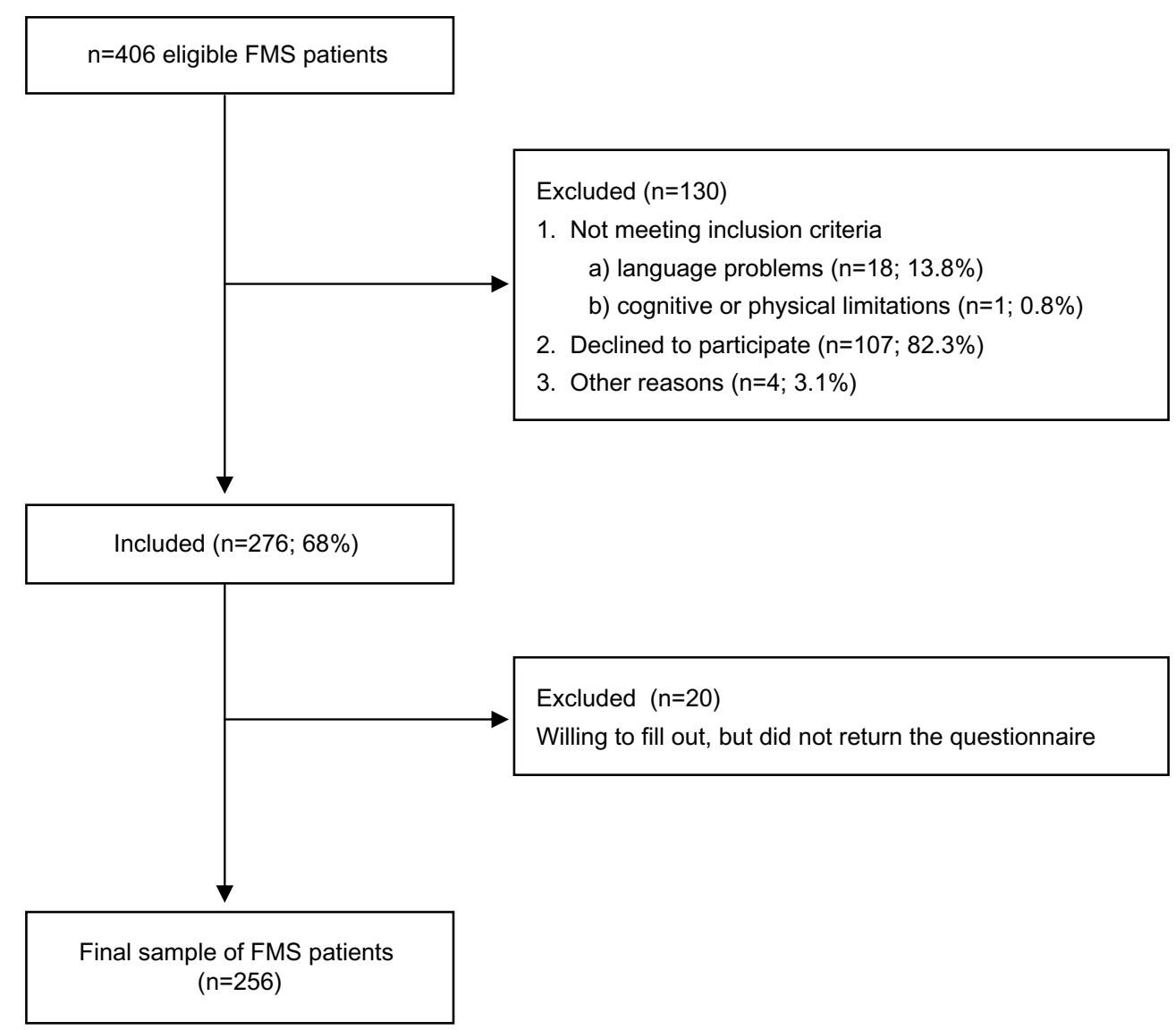

Figure I Participant flow diagram.

Abbreviation: FMS, fibromyalgia syndrome.

\section{Instruments}

We assessed sociodemographic, medical, pain impact, and psychologic variables using various patient self-report instruments. The sociodemographic variables we captured were age, sex, regular partner, highest level of education completed, employment and income. Medical variables were duration of illness and comorbidities measured using a rehabilitation-specific comorbidity score (KoMo-Score; 13 items). ${ }^{25}$ The original KoMo-Score was expanded by four items. Those supplemental questions addressed the various comorbidities (and their severity) frequently associated with FMS. To assess pain impact, we used the German version of the Fibromyalgia Impact Questionnaire (FIQ), German Version (-G ,19 items). The FIQ-G is an assessment and evaluation instrument developed to measure FMS patient status, progress, and outcomes. ${ }^{26}$ The psychologic variables we captured were Illness coherence ie, a belief that the illness "makes sense" (Illness Coherence scale [IPQ-COH] of the Revised Illness Perception Questionnaire, German version; five items), ${ }^{27}$ depression and anxiety (both measured using the Hospital Anxiety and Depression scale [HADS], German version; 14 items $),{ }^{28}$ self-efficacy expectancies concerning pain and other disease-related symptoms (Arthritis SelfEfficacy Short-Form scale [ASES], German version; eight items) $^{29}$ and pain acceptance (Chronic Pain Acceptance Questionnaire [CPAQ], German version; 20 items).$^{30}$ The CPAQ is an instrument to capture the acceptance in coping with chronic pain. For coping with pain we used a German questionnaire that addresses coping strategies (cognitive and behavioral coping) and psychologic strain through chronic pain (German Pain Coping Questionnaire [FESV], German version; 38 items). ${ }^{31-33}$

We administered the KOPRA [(Kommunikationspraeferenzen), communication preferences of patients with chronic illness] questionnaire to measure the communication preferences of patients. ${ }^{34}$ It possesses good psychometric properties and consists of 32 items categorized in four scales. "Patient participation and patient orientation" (PPO, 11 items) measures patient communication preferences with respect to the patient's participation in treatment and consideration of their opinions and preferences. "Effective and open communication" (EOC, ten items) measures preferences with respect to effectively collecting, conveying, and sharing information and open communication about 
Table I Respondent characteristics $(n=256)$

\begin{tabular}{|c|c|}
\hline \multicolumn{2}{|l|}{ Sociodemographic characteristics } \\
\hline Age, years (M, SD) & $52.6(8.4)$ \\
\hline \multicolumn{2}{|l|}{$\operatorname{Sex}(\%)$} \\
\hline Female & 91.3 \\
\hline \multicolumn{2}{|l|}{ Level of education (highest level completed) (\%) } \\
\hline Elementary school & 30.9 \\
\hline Secondary school & 38.6 \\
\hline Employed (\%) & 80.3 \\
\hline Regular partner (\%) & 75.9 \\
\hline \multicolumn{2}{|l|}{ Medical characteristics } \\
\hline \multicolumn{2}{|l|}{ Duration of symptoms (\%) } \\
\hline$<$ I year & 2.4 \\
\hline $\mathrm{I}-2$ years & 4.8 \\
\hline $3-5$ years & 13.5 \\
\hline $6-10$ years & 20.7 \\
\hline$>10$ years & 53.4 \\
\hline KoMo-Score ${ }^{25, a}(0-10, M, S D)$ & $1.20(0.69)$ \\
\hline Expanded KoMo-Score ${ }^{a}$ & $0.30(0.68)$ \\
\hline \multicolumn{2}{|l|}{ (Additional questions regarding FMS; $0-10, M, S D$ ) } \\
\hline \multicolumn{2}{|l|}{ Pain impact variables } \\
\hline FIQ-G ${ }^{26, b}(0-80, M, S D)$ & $52.45(|2.9|)$ \\
\hline \multicolumn{2}{|l|}{ Psychologic variables } \\
\hline IPQ-COH ${ }^{27, c}(I-25, M, S D)$ & $15.88(4.96)$ \\
\hline \multicolumn{2}{|l|}{$\operatorname{HADS}^{28, \mathrm{~d}}(0-2 \mathrm{I}, \mathrm{M}, \mathrm{SD})$} \\
\hline Depression & $9.44(4.52)$ \\
\hline Anxiety & $10.82(4.01)$ \\
\hline $\operatorname{ASES}^{29, e}(I-10, M, S D)$ & $5.05(1.72)$ \\
\hline \multicolumn{2}{|l|}{$\begin{array}{l}\mathrm{FESV}^{31-33, f} \mathrm{HD} \text { and AR: 5-30; AOC, CR, SE, MD, CA, } \\
\text { RE, AN: 4-24, (M, SD) }\end{array}$} \\
\hline $\begin{array}{l}\text { Pain-related psychologic strain - helplessness } \\
\text { and depression (HD) }\end{array}$ & $20.78(5.98)$ \\
\hline $\begin{array}{l}\text { Cognitive coping strategy - action-oriented } \\
\text { coping (AOC) }\end{array}$ & $13.80(4.7 \mid)$ \\
\hline Pain-related psychologic strain - anger (AR) & $18.66(6.5 \mathrm{I})$ \\
\hline $\begin{array}{l}\text { Cognitive coping strategy - cognitive } \\
\text { restructuring }(C R)\end{array}$ & $13.63(4.55)$ \\
\hline Cognitive coping strategy - self-efficacy (SE) & I4.48 (4.47) \\
\hline Behavioral coping - mental distraction (MD) & $12.14(4.35)$ \\
\hline Behavioral coping - counter-activities (CA) & II.84 (4.55) \\
\hline Behavioral coping - relaxation (RE) & $11.69(5.02)$ \\
\hline $\begin{array}{l}\text { Pain-related psychologic strain - } \\
\text { apprehension (AN) }\end{array}$ & $15.68(5.08)$ \\
\hline $\mathrm{CPAQ}^{30,8}(0-120, \mathrm{M}, \mathrm{SD})$ & $53.39(\mid 8.6 I)$ \\
\hline
\end{tabular}

Notes: ${ }^{a}$ With regard to the KoMo-Score and expanded KoMo-Score, higher values mean higher comorbidity and multimorbidity; ${ }^{b}$ with regard to the FIQ-G, a higher value means higher disease impact; 'with regard to the IPQ- $\mathrm{COH}$, a higher value signifies higher perceived coherence; ${ }^{d}$ concerning the HADS-D, higher values mean higher levels of anxiety or depression (values $\leq 7$ : inconspicuous, values between 8-10: borderline, values $\geq 11$ : conspicuous); ${ }^{61}$ ewith regard to the ASES-D, a higher value means higher perceived efficacy; ${ }^{f}$ with regard to the FESV, higher values mean a better coping with pain; ${ }^{~}$ with regard to the CPAQ, a higher value means higher acceptance of pain.

Abbreviations: M, Mean; SD, standard deviation; FMS, fibromyalgia syndrome; KoMo-Score, rehabilitation-specific comorbidity score; FIQ-G, Fibromyalgia Impact Questionnaire, German Version; IPQ-COH, Coherence scale of the Revised Illness Perception Questionnaire, German version; HADS, Hospital Anxiety and Depression Scale, German version; ASES, Arthritis self-efficacy short-form scale, German version; FESV, German Pain Coping Questionnaire, German version; CPAQ, Chronic Pain Acceptance Questionnaire, German version. negative events. "Emotionally supportive communication" (ESC, six items) measures preferences regarding emotionally supportive communication. "Communication about personal circumstances" (CPC, five items) measures preferences regarding a personal communication style that also includes private aspects. The PPO and EOC scales tend to focus on instrumental aspects of communication, whereas the ESC and CPC scales address affective components of communication. The KOPRA questionnaire has been used in several patient samples (low back pain, ${ }^{17}$ cancer, ${ }^{35}$ chronic ischemic heart disease ${ }^{36}$ ), but until now, not in FMS patients.

\section{Statistical analysis}

We applied Cronbach's alpha to test the reliability of the four KOPRA scales for FMS patients. Cronbach's alpha should exceed $0.70 .^{37}$

The parameters (mean and standard deviation) for KOPRA were calculated to answer the first question of our study. We also compared these with other diagnoses. Data for other diagnosis groups come from earlier studies done by the authors using the KOPRA questionnaire..$^{17,35,36}$ In addressing the prediction of communication preferences, we first calculated bivariate correlations between the predictors and KOPRA scales. Those predictors that correlated poorly with the KOPRA scales $(P>0.20)$ were disregarded in subsequent analyses. Missing values in the remaining predictors were imputed using NORM software. ${ }^{38} \mathrm{~A}$ hierarchical regression analysis with four steps was performed. In the first block we placed sociodemographic variables, in the second all medical variables, in the third pain-impact variables and in the fourth all psychologic variables. The backward method of variable selection was employed. ${ }^{39}$ A separate model was specified for each of the KOPRA scales. To diagnose multicollinearity, the variance inflation factor was calculated. Values over 5 can be considered as an indication of multicollinearity. ${ }^{40}$ Statistical analyses were performed using IBM Statistical Package for the Social Sciences version 20 software (IBM Corporation, Armonk, NY, USA).

\section{Results}

\section{Communication preferences in patients with FMS}

Cronbach's alpha for the scale "Patient participation and patient orientation" reached 0.94, the "Effective and open communication" scale 0.94 , the "Emotionally supportive communication" scale 0.88 , and the "Communication about 
Table 2 Mean (M) and standard deviation (SD) of KOPRA items and scales

\begin{tabular}{|c|c|c|}
\hline KOPRA items & M & SD \\
\hline Scale: Patient participation and patient orientation (PPO) & 76.65 & 18.76 \\
\hline Set treatment and therapy measures in a joint discussion with you. & 4.31 & 0.79 \\
\hline Weigh the advantages and disadvantages of different treatment options with you. & 4.27 & 0.82 \\
\hline Discuss the treatment plan with you. & 4.21 & 0.84 \\
\hline Discuss the next stage of treatment with you. & 4.20 & 0.84 \\
\hline Ask you what helped you in your treatment and what did not. & 4.18 & 0.85 \\
\hline Explain the procedure of your treatment to you thoroughly. & 4.15 & 0.89 \\
\hline Ask you everything about your illness. & 4.04 & 1.03 \\
\hline Summarize the results at the end of a discussion with you. & 4.00 & 1.06 \\
\hline Ask you how you assess the results of treatment. & 3.98 & 0.91 \\
\hline Explain the procedure for your treatment. & 3.96 & 0.99 \\
\hline Sometimes address personal issues related to your illness. & 3.44 & 1.22 \\
\hline Scale: Effective and open communication (EOC) & 83.35 & 16.44 \\
\hline $\begin{array}{l}\text { Inform you openly and directly about things concerning your illness that could be } \\
\text { stressful (eg, side effects of a treatment). }\end{array}$ & 4.49 & 0.72 \\
\hline Listen carefully when you want to say something. & 4.45 & 0.78 \\
\hline Inform you at the end of treatment about the further treatment of your illness. & 4.42 & 0.78 \\
\hline Enable you to ask questions. & 4.42 & 0.72 \\
\hline Explain to you exactly what your diagnosis means. & 4.39 & 0.81 \\
\hline Always tell you everything about your illness, even if it is unpleasant. & 4.36 & 0.80 \\
\hline Ask you at the beginning of treatment to discuss all of your symptoms in detail. & 4.31 & 0.81 \\
\hline Ask about all your symptoms. & 4.19 & 0.89 \\
\hline Ask whether you experience pain during therapy/treatment. & 4.18 & 0.86 \\
\hline Ask you what you want to know about your treatment. & 4.07 & 0.97 \\
\hline Scale: Emotionally supportive communication (ESC) & 54.38 & 21.85 \\
\hline Exude calm during talks. & 3.69 & 1.00 \\
\hline Give you encouragement during talks. & 3.38 & 1.10 \\
\hline Sometimes laugh when talking with you. & 3.17 & 1.19 \\
\hline Always be very even-tempered during talks. & 3.12 & 1.01 \\
\hline Always greet you warmly. & 2.91 & 1.13 \\
\hline Always be optimistic and upbeat during talks with you. & 2.75 & 1.14 \\
\hline Scale: Communication about personal circumstances (CPC) & 36.98 & 23.68 \\
\hline Ask about your personal circumstances in order to find out something about you. & 2.88 & 1.18 \\
\hline Try to develop a personal relationship with you. & 2.74 & 1.23 \\
\hline Sometimes speak with you on a personal level. & 2.46 & 1.18 \\
\hline Occasionally talk to you about private matters. & 2.16 & 1.09 \\
\hline Sometimes talk with you about things that have nothing to do with your illness. & 2.15 & 1.14 \\
\hline
\end{tabular}

Notes: KOPRA items are shown in order of preference within the scales, important aspects of communication first. Instruction: "On the following pages of this questionnaire we would like you to tell us what is important to you personally when talking with your physician, and what is less important. We are interested in your personal opinion. In this questionnaire you should assess how important various actions of your physician are to you, not whether your physician demonstrates this behavior. Please indicate below how important you consider the given behavior of your physician. Your physician should ...". Response categories: I= not so important, $2=$ somewhat important, $3=$ important, $4=$ very important, $5=$ extremely important. Range for all KOPRA scales: $0-100$. Higher mean values indicate higher preferences. Adapted with permission of Elsevier. Farin E, Gramm L, Kosiol D. Development of a questionnaire to assess communication preferences of patients with chronic illness. Patient Educ Couns. 20I I;82:8I-88. ${ }^{34}$

Abbreviation: KOPRA, (Kommunikationpraeferenzen) communication preferences of patients with chronic illness.

personal circumstances" scale 0.87 . What becomes apparent is that all the scales (in FMS patients as well) are very reliable, and that the high values resemble those associated with other diagnoses. ${ }^{17,35,36}$

Table 2 illustrates the communication preferences of FMS patients. "Effective and open communication" is most important to patients with FMS, followed by "Patientcentered communication". The mean values for both scales lie in the upper range (answer categories, "extremely important" and "very important"). "Emotionally supportive communication" scale items were rated by the patients as "important" (the mean). Least important to patients with FMS was a personal communication style on the part of the health care provider. The averages of the mean values in this scale lie between the answers "important" and "somewhat important".

Figure 2 shows the means of the KOPRA scales for various diagnostic patient samples (FMS, low back pain, chronic ischemic heart disease and cancer). Means for FMS patients in the KOPRA reveal a distribution pattern similar 


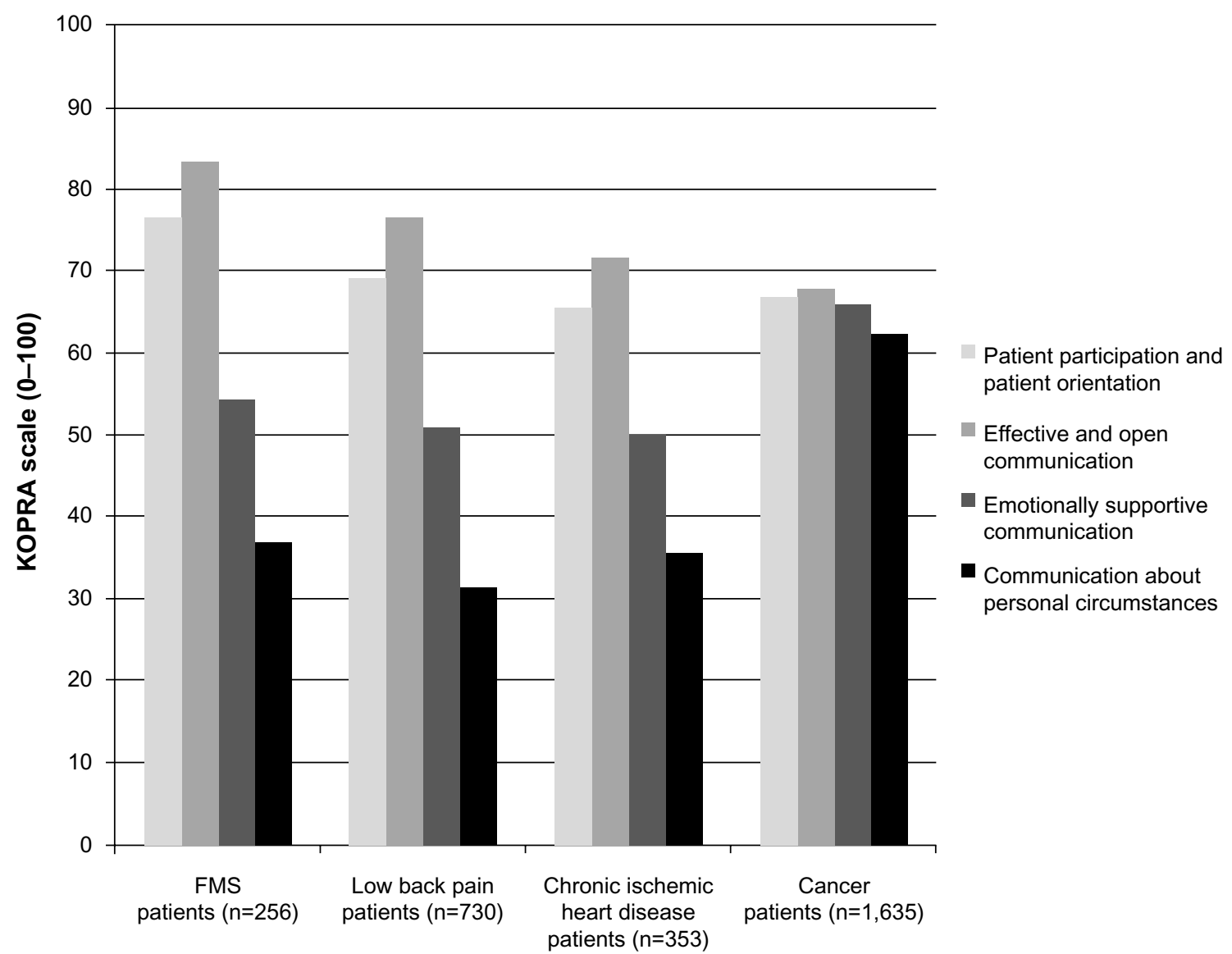

Figure 2 KOPRA scale means of four samples.

Note: Range for all KOPRA scales: 0-100. Higher mean values indicate higher preferences.

Abbreviations: FMS, fibromyalgia syndrome; KOPRA, (Kommunikationpraeferenzen) communication preferences of patients with chronic illness.

to that found in the low back pain and chronic ischemic heart disease patient groups. ${ }^{17,36}$ Values for the FMS patients' values are higher than the values of the other two groups in each of the KOPRA scales. Cancer patients show a different distribution pattern, as all their mean values range between $M=62$ and $M=68$. The four communication areas covered in the KOPRA questionnaire are similarly important to the cancer patients. ${ }^{35}$

Table 3 Results of hierarchical regression analysis

\begin{tabular}{|c|c|c|c|c|}
\hline & $\begin{array}{l}\text { Patient participation } \\
\text { and patient orientation } \\
\text { (PPO) }\end{array}$ & $\begin{array}{l}\text { Effective and open } \\
\text { communication } \\
\text { (EOC) }\end{array}$ & $\begin{array}{l}\text { Emotionally supportive } \\
\text { communication } \\
\text { (ESC) }\end{array}$ & $\begin{array}{l}\text { Communication } \\
\text { about personal } \\
\text { circumstances (CPC) }\end{array}$ \\
\hline \multicolumn{5}{|l|}{ Block I } \\
\hline \multicolumn{5}{|l|}{ Level of education: } \\
\hline Elementary school & - & - & $0.127^{*}(P=0.042)$ & $0.248 * * *(P<0.00 I)$ \\
\hline \multicolumn{5}{|l|}{ Block 2} \\
\hline $\begin{array}{l}\text { Expanded KoMo-Score: } \\
\text { FMS-specific addendum }\end{array}$ & - & - & $-0.106(P=0.087)$ & - \\
\hline \multicolumn{5}{|l|}{ Block 4} \\
\hline CPAQ score & $-0.177^{* *}(P=0.005)$ & $-0.144 *(P=0.020)$ & - & - \\
\hline Scale: anger (FESV) & - & - & $0.204 * *(P=0.00 \mathrm{I})$ & $0.18 \mathrm{I} * *(P=0.003)$ \\
\hline $\begin{array}{l}\text { Scale: implementation } \\
\text { of relaxation (FESV) }\end{array}$ & - & $-0.169 * *(P=0.007)$ & - & - \\
\hline$R^{2}$ & $0.03 I^{* *}(P=0.005)$ & $0.055^{* *}(P=0.00 \mathrm{I})$ & $0.069 * * *(P<0.00 \mathrm{I})$ & $0.097 * * *(P<0.001)$ \\
\hline
\end{tabular}

Notes: Standardized regression coefficients (Beta) and coefficient of determination $\left(R^{\prime}\right)$ with significance $(P) ; * * * P<0.001 ; * * P<0.01 ; * P<0.05 ;-=$ not in the model. Block 3 was not included because there were no significant predictors.

Abbreviations: KoMo-Score, rehabilitation-specific comorbidity score; FMS, fibromyalgia syndrome; CPAQ, Chronic Pain Acceptance Questionnaire, German version; FESV, German Pain Coping Questionnaire. 


\section{Predicting patients' communication preferences}

Table 3 presents the hierarchical regression analysis results. All the variance inflation factor values fell below 1.10, so we can assume very minor multicollinearity among the predictors. Communication preferences' explanation of variance was minor in all four models, lying between $3.1 \%$ and $9.7 \%$.

A more pronounced communication preference is only predicted by the CPAQ score on the "Patient participation and patient orientation" scale. Acceptance of chronic pain in FMS patients was negatively associated with the preference for a patient-centered style of communication.

We identified two predictors for the "Effective and open communication" scale. The preference for effective and open communication is stronger the less accepting patients are of chronic pain and the less often they implement relaxation techniques (FESV). Sociodemographic, medical or pain impact variables (blocks 1-3) did not prove to predict communication preferences in either the PPO or EOC scale.

More pronounced "Anger" (FESV) was associated with more pronounced communication preferences on the ESC scale. Moreover, having an elementary school certificate was also associated with a more pronounced preference on the "Emotionally supportive communication" scale. We identified the same two predictors to be relevant in the "Communication about personal circumstances" scale.

\section{Discussion}

\section{Communication preferences in patients with FMS}

In this study, we observed that FMS patients prefer an effective, open and patient-centered style of communication (EOC and PPO scales) with their health care providers. They also prefer an emotionally supportive communication style on the part of their provider(s) (ESC scale). On the other hand, FMS patients are less likely to prefer a very personal communication style (CPC scale). It is important to note that the standard deviation in the $\mathrm{ESC}$ and $\mathrm{CPC}$ scale is much higher compared with the other two. We can deduce that the preference for a communication style, that patients perceive as being particularly emotionally supportive, or that pays special attention to the patient's personal situation, varies widely from individual to individual. Keeping this in mind, the health care provider should take special care to adapt his or her behavior to the patient's individual communication preferences. ${ }^{41}$

We assume that our results reflect the great need for information that patients with FMS perceive. These patients prefer to be thoroughly informed about their illness and its symptoms by their health care providers, as well as about potential therapeutic alternatives. Therefore it is essential that health care providers are well-informed about FMS and its therapy. In March 2011, a new guideline (S-3-Leitlinie) $)^{42}$ was set up by the Working Group of the Scientific Medical Societies (Arbeitsgemeinschaft der Wissenschaftlichen Medizinischen Fachgesellschaften AWMF, 2011) in Germany, containing information about FMS. These guidelines assist in the definition, classification, diagnosis, and prognosis of the condition, provide various treatment approaches and reports on their efficacy beyond the American College of Rheumatology criteria from $1990^{23}$ and $2010 .^{2}$

Patients consider open communication about the pros and cons associated with a therapy as important. A fundamental assumption for shared decision-making between a patient and his or her physician is an effective patient-centered communication of information about a disease and its therapy. ${ }^{12}$ Many methods have been developed in recent years that improve the quality of the decisions made within a given treatment situation..$^{43}$ Those proven successful are methods describing interventions or the provision of educational information materials for patients and their health care providers. ${ }^{13}$ To make a decision together within a dyadic consultation, health care providers and patients must possess certain skills. ${ }^{44}$

Health care providers should take communication preferences of patients with FMS into account and try to create an open communicative atmosphere that enables active engagement in a consultation. ${ }^{45}$ Thus, time must be set aside at the start of patient-provider communication to "capture" the patient's individual communication preferences. ${ }^{19} \mathrm{With}$ a deeper understanding of the communication preferences of patients with FMS, health care providers can better adapt their communication behavior to these patients' individual needs. The challenge for the health care provider is to find the time within his or her institution's organizational and economic framework to engage in such patient-provider communication. One of the examinations addressing this topic reported that patient-centered communication is associated with less diagnostic testing expenditure. ${ }^{46}$ Paying greater attention to patients' preferences can also lead to better health outcomes via several routes. Adherence on the behavioral level and on the psychologic level, a sense of autonomy and satisfaction with decisions can be influenced by respecting patients' preferences. ${ }^{47}$

When we compare the FMS patients' KOPRA questionnaire results with those of other diagnostic groups, it is apparent that all the FMS patients' KOPRA scale values lie above the means of those for patients with low back pain or 
chronic ischemic heart disease. ${ }^{17,35}$ The distribution pattern of their communication preferences does not differ, but the strength of their preferences is greater than that expressed in the other diagnoses. This result is not surprising when we remember that patients in chronic pain place particular importance on sensing an acceptance and understanding of their pain during communication. ${ }^{48}$ That the means in the instrumental (PPO and EOC scales) and affective dimension (ESC and CPC scales) are higher in the FMS patients highlights this group's special position among patients suffering from chronic pain.

Cancer patients are an exception. ${ }^{34}$ They score much higher on the affective dimension of communication than other diagnostic groups. Facing a life-threatening disease, cancer patients experience their illness by showing a strong tendency to feel negative emotions like fear, sadness, and anxiety $^{49}$ and thus usually sense a much greater need for emotional support. ${ }^{50}$ We also have to take into account that the illness experienced by cancer patients might vary depending on their types of cancer.

\section{Predicting patients' communication preferences}

Our results are similar to those obtained in other studies identifying patient-related predictors of patient communication preferences. ${ }^{20,21}$ Few patient-related factors predict the communication preferences of FMS patients. The explanation of variance is quite small with a maximum of $9.7 \%$.

McKinstry ${ }^{51}$ reported an association between a patient's social class and a stronger preference for a shared condition when consulting with the health care provider. We observed that the only sociodemographic variable with predictive power was the patient's level of education (in terms of an emotionally supportive communication style and communication about personal circumstances). Less well educated patients with FMS tend to prefer a communication style that is more strongly oriented toward their affective needs.

In contrast with other studies, ie, those that reveal age ${ }^{21}$ as a relevant factor in the context of patient preferences, we found in our study that psychologic factors played a stronger role as predictors of communication preferences. There is little published research on the relationship between psychologic factors and communication preferences. ${ }^{52}$ In our study we found that dysfunctional coping with pain (low acceptance of pain, poor implementation of relaxation and increased anger) in FMS patients tended to be associated with a stronger preference for all of the health care providers' communication behaviors thus far examined.

Acceptance is the cognitive attitude necessary for perception and coping with pain. ${ }^{53}$ Further, it influences the patient's participation in life and activities. ${ }^{54}$ Lower levels of acceptance correlate with a higher level of distress and poorer physical and social functioning. ${ }^{55}$ We discovered in our study that a more pronounced preference for the instrumental dimension of communication (PPO and EOC scale of the KOPRA questionnaire) was predicted by a rather low acceptance of pain. Patients with FMS must deal with the problem that symptoms of their disease are often invisible to others ${ }^{56}$ and that there are still difficulties in diagnosing FMS. ${ }^{4}$ Yet, a requirement for acceptance of a disease is that it has been diagnosed by one's physician. Feelings of being misunderstood, rejected, or ignored ${ }^{9}$ can cause the patient to sense a higher level of distress, thus counteracting the process of acceptance. ${ }^{53}$

Patients who score lower on the scale "Relaxation" (FESV) prefer an effective and open communication style from their health care providers. The "Relaxation" scale reflect the extent to which patients implement methods to relax physically. ${ }^{31}$ One potential reason for this observation is that FMS patients who are insecure about applying behavioral management strategies have a stronger need for information.

FMS is often accompanied by negative emotions such as anger, stress, fear and depression. ${ }^{57}$ Anger - as an affective dimension from the FESV's psychologic strain through chronic pain - functioned as a predictor for an emotional and personal communication style (ESC and CPC scales) in our study. Other working groups have demonstrated that the intensity of anger and the general tendency to suppress it predict a stronger perception of pain in the daily life of female FMS patients. ${ }^{58,59}$ The desire to be able to speak about emotions and personal relationships with a provider on the part of patients who are under great emotional strain should be examined and could be treated as a specific topic.

\section{Limitations}

One of the strengths of this study is that we employed a psychometrically well tested questionnaire already administered in samples with other chronic diseases. We thus have produced a differentiated description of the communication preferences of FMS patients and have compared these with patients suffering from other chronic illnesses. We also considered a large number of patient-related predictors from four areas (sociodemographic, medical, pain impact and psychologic) to predict communication preferences. 
However, our study also has a few weaknesses that should be mentioned. Our data were exclusively recruited at the beginning of treatment in one inpatient rehabilitation center in Germany. Patient preferences can change in response to the health care provider's communication, due to changes in one's condition, or because of certain consequences of treatment. ${ }^{47}$ We did not investigate these aspects of patient preferences in this study, but we do intend to consider them in future studies. Another problem is that we do not have any information on the characteristics of our relatively large group of nonresponders (32\%). Our sample size of male participants was very small $(\mathrm{n}=22)$. In future studies it might be interesting to consider more about sex specific differences in patients' communication preferences.

\section{Conclusion}

Patients with FMS prefer open and patient-centered communication with their health care providers. This finding illustrates that health care providers dealing with FMS patients face a particular challenge. For one, FMS patients prefer patient-centered exchanges of information about their disease, while current medical knowledge about the precise causes of FMS is quite limited.

Emotionally supportive communication or communication about personal circumstances is less important to patients with FMS. Whether a given patient requires a more emotional communication style or prefers to talk about personal issues is up to the health care provider to determine, because the preferences for these modes of behavior vary widely. A better understanding of the individual communication preferences of patients with FMS should facilitate the provider in adapting his/her communication behavior more closely to patients' needs.

We addressed various patient-centered factors in this study when seeking predictors for patients' communication preferences. We noted few factors associated with communication preferences. Knowledge about the factors we considered to be relevant (education status, psychologic variables) may help health care providers to identify and apply one of the communication styles that their patient prefers. Because the association between the predictors and preferences was not too high, the influencing factors can only give us initial hints or show tendencies, which would then need to be verified in consultation with individual patients. The psychologic variables associated with higher expectations from communication were also revealed to be predictors for psychologic distress in FMS. ${ }^{60}$ Patients with FMS thus present their health care providers with a double challenge.

\section{Acknowledgments}

We wish to thank the cooperating rehabilitation center (RehaKlinikum Bad Säckingen GmbH; Bad Säckingen, Germany) for their support with data collection.

The article processing charge was funded by the open access publication fund of the Albert Ludwigs University of Freiburg.

\section{Disclosure}

The authors report no conflicts of interest in this work.

\section{References}

1. Bensing J. Bridging the gap. The separate worlds of evidence-based medicine and patient-centered medicine. Patient Educ Couns. 2000;39:17-25.

2. Wolfe F, Clauw D, Fitzcharles MA, et al. The American College of Rheumatology preliminary diagnostic criteria for fibromyalgia and measurement of symptom severity. Arthritis Care Res. 2010;62: 600-610.

3. Haugli L, Strand E, Finest A. How do patients with rheumatic disease experience their relationship with their doctors? A qualitative study of experiences of stress and support in the doctor-patient relationship. Patient Educ Couns. 2004;52:169-174.

4. Perrot S, Choy E, Petersel D, Ginovker A, Kramer E. Survey of physician experiences and perceptions about the diagnosis and treatment of fibromyalgia. BMC Health Serv Res. 2012;12:356.

5. Bieber C, Mueller KG, Blumenstiel K, Eich W. Partizipative Entscheidungsfindung als Maßnahme zur Verbesserung der ArztPatienten-Interaktion mit Fibromyalgie-Patienten [Shared decision making improves the physician-patient interaction with fibromyalgia patients]. Z Med Psychol. 2006;15:53-60. German.

6. Asbring P, Narvanen AL. Ideal versus reality: physicians perspectives on patients with chronic fatigue syndrome (CFS) and fibromyalgia. Soc Sci Med. 2003;57:711-720.

7. Choy E, Perrot S, Leon T, et al. A patient survey of the impact of fibromyalgia and the journey to diagnosis. BMC Health Serv Res. 2010;10:102.

8. Mueller A, Hartmann M, Eich W. Inanspruchnahme medizinischer Versorgungsleistungen. Untersuchung bei Patienten mit Fibromyalgiesyndrom (FMS) [Health care utilization in patients with fibromyalgia syndrome (FMS)]. Schmerz. 2000;14:77-83. German.

9. Werner A, Malterud K. It is hard work behaving as a credible patient: encounters between women with chronic pain and their doctors. Soc Sci Med. 2003;57:1409-1419.

10. Annemans L, Le Lay K, Taieb C. Societal and patient burden of fibromyalgia syndrome. Pharmacoeconomics. 2009;27:547-559.

11. Sepucha A, Mully A. Extending decision support: preparation and implementation. Patient Educ Couns. 2003;50:269-271.

12. Bieber C, Mueller KG, Blumenstiel K, et al. A shared decision-making communication training program for physicians treating fibromyalgia patients: effects of randomized controlled trial. J Psychosom Res. 2008;64:13-20.

13. Thorne SE, Harris SR, Mahoney K, Con A, McGuinness L. The context of health care communication in chronic illness. Patient Educ Couns. 2004;54:299-306

14. Williams S, Weinman J, Dale J. Doctor-patient communication and patient satisfaction. A review. Fam Pract. 1998;15:140-192.

15. Beck RS, Daughtridge R, Sloane PD. Physician-patient communication in the primary care office: a systematic review. J Am Board Fam Pract 2002;15: 25-38.

16. Griffin SJ, Kinmonth AL, Veltman MWM, Gillard S, Grant J, Steward M. Effect on health-related outcomes of interventions to alter the interaction between patients and practitioners: a systematic review of trials. Ann Fam Med. 2004;2:595-608. 
17. Farin E, Gramm L, Schmidt E. Taking into account patient's communication preferences: instrument development and results in chronic back pain patients. Patient Educ Couns. 2012;86:41-48.

18. Serber ER, Cronan TA, Walen HR. Predictors of patient satisfaction and health care costs for patients with fibromyalgia. Psychol Health. 2003; 18:771-787.

19. Arora NK, McHorney C. Patient preferences for medical decision making: who really wants to participate? Med Care. 2000;38:335-341.

20. Garfield S, Smith F, Francis SA, Chalmers C. Can patient's preferences for involvement in decision-making regarding the use of medicines be predicted? Patient Educ Couns. 2007;66:361-367.

21. Coulter A, Ellins J. Patient-focused Interventions: A Review of the Evidence (Report). London, UK: Picker Institute Europe and Health Foundation; 2006

22. World Health Organization (WHO). The ICD-10 Classification of Mental and Behavioural Disorders. Geneva: WHO, 1992.

23. Wolfe F, Smythe HA, Yunus MB, et al. The American College of Rheumatology criteria for the classification of fibromyalgia. Report of the Multicenter Criteria Committee. Arthritis Rheum. 1990;33:160-172.

24. Gran JT. The epidemiology of chronic generalized musculoskeletal pain. Best Pract Res Clin Rheumatol. 2003;17:547-561.

25. Glattacker M, Meixner K, Farin E, Jäckel WH. Entwicklung eines rehabilitationsspezifischen Komorbiditätsscores und Prüfung der methodischen Gütekriterien [Development and psychometric testing of a rehabilitation specific comorbidity score]. Phys Med Rehab Kuror. 2007;17:260-270. German.

26. Offenbaecher M, Waltz M, Schoeps P. Validation of a German version of the Fibromyalgia Impact Questionnaire (FIQ-G). J Rheumatol. 2000;27:1984-1988.

27. Moss-Morris R, Weinman J, Petrie KJ, Horne R, Cameron LD, Buick D. The Revised Illness Perception Questionnaire (IPQ-R). Psychol Health. 2002; 17:1-16.

28. Herrmann C, Buss U, Snaith RP. HADS-D - Hospital Anxiety and Depression Scale, Deutsche Version: Ein Fragebogen zur Erfassung von Angst und Depressivität in der somatischen Medizin. Bern: Hans Huber; 1995. German.

29. Müller A, Hartmann M, Müller K, et al. Validation of the arthritis self-efficacy short-form scale in German fibromyalgia patients. Eur $J$ Pain. 2003;7:163-171.

30. Nilges P, Köster B, Schmidt CO. Schmerzakzeptanz - Konzept und Überprüfung einer deutschen Fassung des Chronic Pain Acceptance Questionnaire [Pain acceptance - concept and validation of a German version of the Chronic Pain Acceptance Questionnaire]. Schmerz. 2007;21:57-67. German.

31. Geissner E. FESV Fragebogen zur Erfassung der Schmerzverarbeitung (Manual). Göttingen: Hogrefe; 2001. German.

32. Scascighini L, Litschi M, Walti M, Sprott H. Effect of an interdisciplinary outpatient pain management program (IOPP) for chronic pain patients with and without migration background: A prospective, observational clinical study. Pain Med. 2011;12:706-716.

33. Verra ML, Angst F, Lehmann S, Aeschlimann A. Translation, crosscultural adaptation, reliability, and validity of the German version of the Coping Strategies Questionnaire (CSQ-D). J Pain. 2006;7: 327-336.

34. Farin E, Gramm L, Kosiol D. Development of a questionnaire to assess communication preferences of patients with chronic illness. Patient Educ Couns. 2011;82:81-88.

35. Farin E, Baumann W. Kommunikationspräferenzen onkologischer Patienten [Communication preferences of oncology patients]. Das Gesundheitswesen. In press. German.

36. Farin E, Gramm L, Schmidt E. The congruence of patient communication preferences and physician communication behavior in cardiac patients. J Cardiopulm Rehabil. 2011;31:349-357.
37. Nunnally JC, Bernstein IRA. Psychometric Theory. 3rd ed. New York: McGraw-Hill; 1994.

38. Schafer JL. NORM: multiple imputation of incomplete multivariate data under a normal model, version 2.03, software for Windows 95/98/NT. Available from http://sites.stat.psu.edu/ jls/misoftwa.html. Accessed August 20, 2013.

39. Mantel N. Why stepwise procedures in variable selection. Technometrics. 1970;12:621-625.

40. Menard SW. Applied Logistic Regression Analysis. 2nd ed. Thousand Oaks, CA: Sage, 2002.

41. Farin E, Nagl M. The patient-physician relationship in patients with breast cancer: descriptive results and influence on quality of life after rehabilitation. Qual Life Res. 2013;22:283-294.

42. Sepucha K, Mulley AG Jr. A perspective on the patient's role in treatment decisions. Med Care Res Rev. 2009;66:53-74.

43. Eich W, Häuser W, Arnold B, et al. Fibromyalgia syndrome: Definition, classification, clinical diagnosis and prognosis. Schmerz. 2012; 26: DOI 10.1007/s00482-012-1169-x.

44. Towle A, Godolphin W. Framework for teaching and learning informed shared decision making. BMJ. 1999;319:766-771.

45. Tariman JD, Berry DL, Cochrane B, Doorenbos A, Schepp K. Preferred and actual roles during health care decision making in persons with cancer: a systematic review. Ann Oncol. 2010;21:1145-1151.

46. Epstein RM, Franks P, Shields CG, Meldrum SC, Miller KN, Campbell TL. Patient-centered communication and diagnostic testing. Ann Fam Med. 2005;3:415-421.

47. Street RL Jr, Elwyn G, Epstein RM. Patient preferences and outcomes: an ecological perspective. Expert Rev Pharmacoecon Outcomes Res. 2012;12:167-180.

48. Matthias MS, Bair MJ. The patient-provider relationship in chronic pain management: Where do we go from here? Pain Med. 2010;11: 1747-1749.

49. Kennifer SL, Alexander SC, Pollak KI, et al. Negative emotions in cancer care: Do oncologist` responses depend on severity and type of emotion? Patient Educ Couns. 2009;76:51-56.

50. Hack TF, Degner LF, Parker PA. The communication goals and needs of cancer patients: a review. Psychooncology. 2005;14:831-845.

51. McKinstry B. Do patients wish to be involved in decision making in the consultation? Brit Med J. 2000;321:867-871.

52. Hashimoto H, Fukuhara S. The influence of locus of control on preferences for information and decision making. Patient Educ Couns. 2004;55:236-240.

53. LaChapelle DL, Lavoie S, Boudreau A. The meaning and process of pain acceptance. Perceptions of women living with arthritis and fibromyalgia. Pain Res Manag. 2008;13(3):201-210.

54. Viane I, Crombez G, Eccleston C, et al. Acceptance of pain is an independent predictor of mental well-being in patients with chronic pain: empirical evidence and reappraisal. Pain. 2003;106: 65-72.

55. Rodero B, Casanueva B, Luciano JV, Gili M, Serrano-Blanco A, Carcia-Campayo J. Relationship between behavorial coping strategies and acceptance in patients with fibromyalgia syndrome: Elucidating targets of interventions. BMC Musculoskel Dis. 2011;12:143.

56. Sim J, Madden S. Creating meaning in fibromyalgia syndrome. Soc Sci Med. 2006;63:2962-2973.

57. Toussaint L, Overvold-Ronningen M, Vincent A, et al. Implications of forgiveness enhancement in patients with fibromyalgia and chronic fatigue syndrome. J Health Care Chaplain. 2010;16: 123-139.

58. Van Middendorp H, Lumley MA, Moerbeek M, Jacobs JWG, Bijlsma JWJ, Geenen R. Effects of anger and anger regulation styles on pain in daily life of women with fibromyalgia: A diary study. Eur $J$ Pain. 2010;14:176-182. 
59. Burns JW. Arousal of negative emotions and symptom-specific reactivity in chronic low back pain patients. Emotion. 2006;6:309-319.

60. Van Koulil S, Van Lankveld W, Kraaimaat FW, Van Riel PLCM, Evers AWM. Risk factors for longer term psychological distress in well-functioning fibromyalgia patients: A prospective study into prognostic factors. Patient Educ Couns. 2010;80:126-129.
61. Zigmond AS, Snaith RP. The Hospital Anxiety and Depression Scale. Acta Psychiatr Scand. 1983;67:361-370.

\section{Publish your work in this journal}

Patient Preference and Adherence is an international, peer-reviewed, open access journal focusing on the growing importance of patient preference and adherence throughout the therapeutic continuum. Patient satisfaction, acceptability, quality of life, compliance, persistence and their role in developing new therapeutic modalities and compounds to optimize clinical outcomes for existing disease states are major areas of interest. This journal has been accepted for indexing on PubMed Central. The manuscript management system is completely online and includes a very quick and fair peer-review system. Visit http://www.dovepress.com/ testimonials.php to read real quotes from published authors.

Submit your manuscript here: http://www.dovepress.com/patient-preference-and-adherence-journal 